\title{
Investimento Estrangeiro Direto e Capital Brasileiro no Exterior: Uma Análise Setorial a partir do Índice de Grubel e Lloyd
}

\author{
Álvaro Alves de Moura Jr. ${ }^{1}$ \\ Joaquim Carlos Racy ${ }^{2}$ \\ Pedro Raffy Vartanian ${ }^{3}$
}

\begin{abstract}
Resumo
A partir dos anos 2000, principalmente, ocorreu um processo de transição nas principais economias latino-americanas no que se refere à dinâmica dos fluxos de investimento direto, em que antes eram predominantemente de entrada de capitais externos, passando também a apresentar uma evolução na saída de capitais para o exterior. Neste sentido, o presente trabalho visa fazer uma análise comparativa relacionada à evolução setorial da entrada de empresas estrangeiras no Brasil relativamente às empresas brasileiras que atuam no exterior no período 2000-2014, à luz das principais teorias que tratam do fenômeno "exportação de capital produtivo". Para a consecução do trabalho são utilizados dados extraídos das bases da Conferência das Nações Unidas sobre Comércio e Desenvolvimento (UNCTAD), do Banco Central do Brasil e aplicado o índice de Grubel e Lloyd. A aplicação do referido índice permite uma comparação da evolução histórica dos estoque setoriais de IED acolhidos e remetidos pelo Brasil de forma mais apurada. Entre os resultados obtidos destaca-se a identificação dos setores em que os estoques de IED no país são relativamente convergentes com os capitais nacionais estabelecidos fora do território nacional.
\end{abstract}

Palavras-chave: Internacionalização, Setores, Grubel e Lloyd, IED.

\begin{abstract}
Since the 2000s, there has been a transition process in the main Latin American economies in terms of the dynamics of direct investment flows, where capital inflows have been accompanied by local investment abroad. In this sense, the present work aims to make a comparative analysis related to the sectoral evolution of the entry of foreign companies in Brazil in relation to the Brazilian companies that work abroad in the period 2000-2014, in the light of the main theories that deal with the phenomenon "export of productive capital". To obtain the work, data extracted from the bases of the United Nations Conference on Trade and Development (UNCTAD) of the Central Bank of Brazil and applied the Grubel and Lloyd index are used. The application of this index allows a comparison of the historical evolution of sector stocks of FDIs received and remitted by Brazil in a more accurate way. Among the results obtained, we highlight the identification of the sectors in which FDI stocks in the country are relatively convergent with national capital established outside the national territory.
\end{abstract}

\section{Keywords: Internationalization, Sectors, Grubel and Lloyd, FDI.}

\footnotetext{
${ }^{1}$ Economista, Mestre em Economia Política e Doutor em Ciências Sociais pela PUC/SP. Professor do Programa de Mestrado em Economia e Mercados da Universidade Presbiteriana Mackenzie.

${ }^{2}$ Economista, Cientista Político, Mestre e Doutor em História pela PUC/SP. Professor Programa de Mestrado em Economia e Mercados da Universidade Presbiteriana Mackenzie e do Programa de Mestrado em Economia Política da PUC/SP.

${ }^{3}$ Economista, Mestre em Economia Política pela PUC/SP e Doutor pelo PROLAM. Professor Programa de Mestrado em Economia e Mercados da Universidade Presbiteriana Mackenzie.
} 
Área Temática: 2.1 Investimento Direto Estrangeiro e internacionalização de empresas JEL: F23 - Multinational Firms; International Business

\section{Introdução}

A partir dos anos 2000, principalmente, ocorreu um processo de transição nas principais economias latino-americanas no que se refere à dinâmica dos fluxos de investimento direto (IED), em que os ingressos desses capitais passaram a ser acompanhados de investimento local no exterior. Assim, diversos países da América Latina, com destaque para o Brasil, vivenciaram um processo de internacionalização de empresas locais em diversos setores de atividade no exterior. Esta estratégia, restrita até então aos países desenvolvidos, começou a se disseminar entre países e setores de atividade econômica.

A literatura que envolve a análise do processo de internacionalização de empresas acompanhou a evolução da transição e pode ser dividida em duas vertentes principais: uma análise sob a ótica da gestão, que avalia os determinantes organizacionais e estratégicos da internacionalização de empresas brasileiras, como na análise de Honório (2009) e, a outra, sob uma ótica econômica, que avalia os determinantes da internacionalização do capital produtivo a partir dos estudos de Hymer na década de 1960.

Nesse contexto, muitos estudos trataram o tema internacionalização com um enfoque global, sem a identificação de setores, como, por exemplo, as análises de Hilal e Hemais (2003), Carneiro e Dib (2008) e Almeida (2007). Por outro lado, os trabalhos que abordaram o tema sob a ótica setorial, analisaram o processo à luz de um ou alguns setores, como as pesquisas de Rocha et. al. (2005), Macadar (2009) e Pasqualotto e Ugalde (2010).

Percebe-se, portanto, que inexiste um panorama setorial detalhadado do processo de internacionalização de empresas brasileiras. No mesmo sentido, não foram encontradas pesquisas que avaliem, para um conjunto de setores da economia, como o investimento brasileiro no exterior por setores ocorreu de forma relativa ao investimento estrangeiro direto no Brasl.

Neste sentido, o presente trabalho visa fazer uma análise comparativa relacionada à evolução setorial da entrada de empresas estrangeiras no Brasil relativamente às empresas brasileiras que atuam no exterior no período 2000-2014 à luz das principais teorias que tratam do fenômeno "exportação de capital produtivo". Para a consecução do trabalho são utilizados dados extraídos das bases da Conferência das Nações Unidas sobre Comércio e Desenvolvimento (UNCTAD), do Banco Central do Brasil e aplicado o índice de Grubel e Lloyd adaptado para os estoques setoriais de IED, a partir do clássico trabalho de Grubel e Lloyd (1975). A aplicação do referido índice permite uma comparação da evolução histórica dos estoque setoriais de IED acolhidos e remetidos pelo Brasil de forma mais apurada.

Assim, após esta introdução, o marco teórico discorre sobre o processo de internacionalização do capital e sobre o investimento estrangeiro direto. Paralelamente, a seção apresenta uma análise da situação do Brasil em relação ao resto do mundo no que tange à atração 
de investimento estrangeiro. A seção 3 apresenta a metodologia da pesquisa, que consiste na aplicação do índice de Grubel e Lloyd adaptado para os estoques setoriais de investimento estrangeiro. Já na seção 4, com a aplicação do índice supra-mencionado, são apresentadas as análises de resultados e a dicussão. Finalmente, na última seção, são apresentadas as considerações finais da pesquisa.

\section{Internacionalização do Capital e Investimento Estrangeiro Direto}

A análise das relações econômicas internacionais geralmente está focada no comércio internacional, motivo pelo qual um amplo número de modelos foi desenvolvido para tratar do assunto esse tema. Todavia, o presente tema passou a ter uma grande relevância, sobretudo a partir da década de 1960, quando vários autores passaram a contribuir para o desenvolvimento da questão o presente tema. As principais teorias que tratam do processo de internacionalização do capital podem ser encontradas nas mais diversas linhas do pensamento econômico, e parte dos seus modelos estão baseados na hipótese desenvolvida inicialmente por Hymer, na década de 1960, de que os IEDs norte-americanos eram produtos de mercados imperfeitos na economia internacional de bens e de fatores, que permitiam às empresas multinacionais se apropriarem de lucros oligopolistas provenientes das possíveis vantagens (tecnológicas, gerenciais ou concorrenciais) que tinham em relação aos competidores nacionais.

Além de Hymer, os trabalhos de Kindleberger (1974) e Caves (1971) também são considerados os principais precursores dos modelos que procuram compreender os fluxos de IED, tanto que os mesmos passaram a constituir uma tradição no que tange à discussão em questão, que ficou conhecida como $H K C$. Em seu trabalho, Hymer (1983) busca separar as discussões sobre o IED das teorias clássicas de comércio internacional, bem como dos tópicos de finanças. Para o autor, geralmente, as atividades de uma empresa no exterior são mais dispendiosas e envolvem maior complexidade operacional do que em seu país de origem. Neste sentido, uma empresa apenas buscará internacionalizar suas atividades se puder explorar as falhas de mercado existentes nos países receptores, com o claro objetivo de obter vantagens comparativas.

É por esse motivo que, para Hymer (1983), as companhias internacionalizadas procuram "privilégios" para operacionalizar suas atividades num país estrangeiro - o que envolve, entre outras coisas, o respeito à propriedade intelectual, mercados específicos, financiamentos etc. de tal modo que essas condições tendem a ampliar as imperfeições nos mercados, e garantir o controle do mesmo pelas empresas estrangeiras.

Kindleberger (apud DUNNING, 1993) também empreendeu uma análise baseada na hipótese de que um contexto de concorrência perfeita (nos mercados de bens, serviços e fatores) inibe os fluxos de IED, uma vez que as empresas (estrangeiras) entrantes estariam em desvantagem em relação às empresas já estabelecidas, sobretudo em função das distâncias entre os novos polos produtores e os centros decisórios.

Dessa forma, a expansão das atividades produtivas além das fronteiras nacionais só faz sentido em ambientes caracterizados pelas falhas de mercado, nos quais o Estado tem um papel central, uma vez que sua ingerência sempre é chamada para garantir a existência e a manutenção das vantagens ocasionadas por essas condições. Essa mesma linha de orientação pode ser encontrada em Caves (1971), uma vez que o autor também vê uma forte relação entre a estrutura dos mercados e a entrada de empresas estrangeiras. Cabe realçar que, para o autor, essa relação está associada ao grau de diferenciação dos produtos, às condições de entrada e à eficiência do sistema de segurança da propriedade intelectual.

Também tendo como foco central das suas discussões as falhas de mercado, Buckey; Casson (1976) elaboram a chamada Teoria da Internalização. Segundo os autores, uma empresa internacionaliza-se quando busca garantir o controle exclusivo de alguns fatores de produção, 
de tal modo que consiga, com isso, reduzir os seus custos de transação. Esse processo, que se dá pela internacionalização da empresa, pode permitir a internalização desses recursos. Para os autores o processo de internalização corresponde a uma reação à imperfeição dos mercados, sobretudo no mercado de bens intermediários, que a partir dos IED permitem a formação de uma cadeia de produção integrada. Para tanto, a decisão empresarial de se internacionalizar, seja essa por meio de alianças ou filiais (próprias ou adquiridas), deve levar em conta um conjunto de varáveis que permitem comparar os custos de transação da empresa com os novos custos de internalização ${ }^{4}$ decorrentes desse processo de internacionalização.

Outra importante contribuição na linha da tradição $H K C$ é encontrada na teoria do ciclo do produto de Vernon (1966). Segundo o autor, uma empresa tende a ter esgotadas as oportunidades em seu mercado interno, motivo pelo qual passa a exportar suas atividades já depreciadas para outros países, com o claro objetivo de iniciar um novo ciclo de lucratividade.

Para esse autor, o processo de produção e de vendas está dividido em três estágios: o primeiro ocorre em países intensivos em capital, por meio de um processo inovativo que cria um produto ainda não padronizado; o segundo se dá quando a venda do produto já padronizado em outros países for vantajosa tanto no campo da produção quanto da inovação; e, por fim, o terceiro ocorre a partir do momento em que a entrada de novos concorrentes reduz os ganhos do poder de monopólio, que são oriundos do processo inovativo, fato que leva as empresas já estabelecidas a buscar novos espaços de negócios, a partir da abertura de filiais em outros países. Portanto, a teoria do ciclo de produto de Vernon descreve um processo de crescimento das empresas que se dá a partir da seguinte sequência de decisões: o atendimento à demanda local; posteriormente aos mercados estrangeiros através das exportações e dos representantes comerciais; e, finalmente, a produção nos próprios mercados de destino por meio da abertura de filiais.

Em suma, pode-se observar que nas teorias ligadas à tradição $H C K$, a decisão de internacionalização do capital está diretamente condicionada: i) ao grau de concentração de mercado; às condições assimétricas de acesso ao capital e à tecnologia, bem como a uma legislação sobre a propriedade intelectual que garanta um sistema eficiente de registro de patentes etc.; ii) à atuação governamental em diversas dimensões; e, iii) a possibilidade de operação em condições de economia de escala (internas e externas).

Dunning (1993) desenvolve um arcabouço teórico mais amplo em relação à tradição $H K C$. Nele o autor busca mesclar as teorias microeconômicas e de comércio internacional, dando forma ao que se denomina Paradigma Eclético, que também é conhecido por OLI (Ownership-Localização-Internalização). O Paradigma Eclético - OLI parte do pressuposto de que as principais razões para uma empresa passar a operar em outro país são: $i$ ) a busca de recursos não disponíveis no seu país (recursos naturais, matérias-primas, mão-de-obra etc.); ii) a prospecção de novos mercados; iii) o alcance da operação produtiva em níveis mais eficientes de escala e de escopo; $i v$ ) a melhoria das suas condições concorrenciais com a obtenção de ativos estratégicos já existentes, por meio das operações de fusões e aquisições.

Em função desses pontos, o autor afirma que uma empresa decide operar de forma direta em outro país, ou via parcerias, quando essa modalidade lhe permite auferir três tipos de vantagens. i) a possibilidade de exploração de competências desenvolvidas na matriz "Ownership" ( $\mathrm{O}$ ), que gerem um diferencial competitivo em relação às empresas rivais; ii) a exploração das vantagens de localização ( L ), sobretudo no que tange ao acesso mais barato aos fatores de produção, e a melhor possibilidade de exploração de um mercado estrangeiro, por meio de uma atuação direta que permite desenvolver tanto o conhecimento sobre o mesmo como as formas de integrá-lo; iii) a exploração das vantagens de internalização ( I ), que

\footnotetext{
${ }^{4}$ Correspondem aos próprios gastos e investimentos realizados para realizar a atividade produtiva fora da matriz, das condições concorrenciais do mercado, dos riscos envolvidos.
} 
promovem a redução dos custos de câmbio, a minimização das incertezas, a ampliação do poder de barganha e um maior controle do mercado em que atua.

Neste sentido, Dunning (1993) concebe a possibilidade de uma dinâmica para o seu paradigma, que é determinada pelas particularidades que envolvem as características da empresa, do setor e do país, que afetam as vantagens locais e as características das atividades das empresas multinacionais. Ademais, considera que:

The distinctive characteristic of the MNE activity is, then, that in marries the transborder dimension of value-added activities of firms with the common governance of those activities. While de former draws upon the economics of the special distribution of immobile resources and the theory of market structures to explain the location of production independently of this ownership, the theory of market failure help to explain the organization and ownership of production independently of its location. (DUNNING, 1993, p. 79)

Outro ponto de destaque do paradigma eclético se refere à inclusão da importância do grau de desenvolvimento econômico dos países acolhedores nas decisões que envolvem a exportação de capital, uma vez que essas tendem a afetar tanto as vantagens de propriedade quanto de localização e de internalização para empresas multinacionais. Para o autor, os países não-industrializados geralmente não apresentavam essas vantagens, motivo pelo qual não eram receptores de IED. Porém, alguns desses países têm se tornado atraentes para algumas empresas estrangeiras, em função da abundância de determinados fatores, principalmente recursos naturais e mão-de-obra.

Apesar de ainda ter como destino predominante as chamadas economias desenvolvidas, verificou-se, nos últimos anos, um expressivo aumento do destino de IED para as economias em desenvolvimento, das quais a China, Hong Kong e o Brasil se destacam. Se avaliados os fluxos acolhidos de IED entre os anos de 2000 e 2014, tem-se que a China é o segundo país que mais recebeu o referido capital, encontrando-se o Brasil na sétima posição desse ranking.

Quando avaliadas as remessas de IED, o que se nota, também, é a presença maciça da participação dos países desenvolvidos na lista dos dez maiores "exportadores" dessa modalidade de capital, exceção feita à China e Hong Kong, que figuram na décima posição do ranking em questão. O Brasil ocupa a trigésima quinta posição neste ranking, que corresponde ao fluxo de remessa de IED acumulado entre os anos de 2000 e 2014, significando uma participação relativa de $0,34 \%$ do fluxo total conforme mostram os dados da Tabela 1 .

Tabela 1 - Fluxo de Entrada e Saída de IED (em US\$ milhões - fluxos acumulados entre os anos de 2000 e 2014) 


\begin{tabular}{l|c|c|l|c|c}
\hline \multicolumn{4}{c|}{ Entrada de IED } & \multicolumn{3}{c}{ Saida de IED } \\
\hline Países & $2000 / 2014$ & Part. \% & Países & $2000 / 2014$ & Part. \% \\
\hline EUA & 2.665 .484 & $14,5 \%$ & EUA & 3.706 .987 & $20,25 \%$ \\
China & 1.298 .634 & $7,0 \%$ & Reino Unido & 1.303 .469 & $7,12 \%$ \\
Reino Unido & 1.236 .909 & $6,7 \%$ & Japão & 1.070 .026 & $5,85 \%$ \\
Hong Kong & 797.262 & $4,3 \%$ & Alemanha & 1.053 .665 & $5,76 \%$ \\
Alemanha & 689.129 & $3,7 \%$ & França & 938.167 & $5,13 \%$ \\
Canadá & 642.474 & $3,5 \%$ & Hong Kong & 873.688 & $4,77 \%$ \\
Bélgica & 598.254 & $3,2 \%$ & Holanda & 786.154 & $4,30 \%$ \\
Brasil & 546.525 & $3,0 \%$ & Espanha & 715.743 & $3,91 \%$ \\
Espanha & 523.857 & $2,8 \%$ & Canadán & 674.973 & $3,69 \%$ \\
Cingapura & 510.944 & $2,8 \%$ & China & 639.312 & $3,49 \%$ \\
\hline Países Desenvolvidos & 10.294 .521 & $55,9 \%$ & Países Desenvolvidos & 13.708 .095 & $74,89 \%$ \\
Países em Desenvolvimento & 6.597 .033 & $35,8 \%$ & Países em Desenvolvimento & 3.331 .929 & $18,20 \%$ \\
Países em Transição & 841.940 & $4,6 \%$ & Países em Transição & 584.200 & $3,19 \%$ \\
\hline Total & 18.423 .008 & - & Total & 18.303 .881 & - \\
\hline
\end{tabular}

Fonte: UNCTAD

Retomando as questões de ordem teórica, vale ressaltar um importante problema, que se refere ao fato de que para as relações entre as empresas multinacionais e os países acolhedores, sejam eles desenvolvidos ou em desenvolvimento, alguns pontos são tidos como cruciais nas escolhas locacionais. São eles: $i$ ) a contribuição para a expansão do comércio internacional do país receptor; ii) o grau de interação entre a empresa estrangeira e as empresas nacionais já estabelecidas no país receptor, que pode envolver, entre outras coisas, a própria transferência de tecnologia; iii) o impacto sobre a produção e a renda; e, iv) a geração de novas empresas locais.

Neste sentido, Lall (1978 apud DICKEN, 1998) identifica quatro tipos de atividades orientadas para a atuação das empresas multinacionais, e sugere que cada uma delas tem implicações muito diferentes para a criação de relações econômicas locais, particularmente nas economias em desenvolvimento. São elas:

1) As que visam originalmente um mercado interno, mas desenvolvem, posteriormente, uma forte orientação para exportação. Neste caso, as empresas geralmente utilizam tecnologias relativamente estáveis e pouco sofisticadas, e a produção se localiza em áreas onde a força de trabalho é altamente qualificada, porém barata. Neste caso, existe a possibilidade de desenvolvimento de uma rede mais extensa de ligações entre as empresas locais e a empresa estrangeira que se estabelece.

2) As indústrias mais tradicionais (têxteis, alimentos, artigos esportivos), que empregam uma tecnologia padronizada, mas que cuja diferenciação de produto (via marketing ou inovações de produto) é fundamental. Essas atividades têm um elevado potencial para a criação de relações locais com fornecedores nacionais para fabricação dos componentes, ou até mesmo dos produtos finais.

3) Aquelas que compõem as indústrias mais modernas, cujas tecnologias são complexas. Em geral, essas atividades são controladas pela matriz que, geralmente, já predeterminam as relações de fornecimento, o que limita o desenvolvimento de ligações locais.

4) As que buscam, essencialmente, operações de terceirização, para as quais apenas uma parte do processo produtivo, geralmente muito trabalhoso, passa a se localizar nos países em desenvolvimento. Neste caso, a possibilidade de ligação local é ínfima, dada a natureza dinâmica do processo de produção envolvido.

De certa forma é difícil, particularmente no caso do Brasil, identificar apenas um desses pontos como determinantes para a entrada dos fluxos de IED, fato que será abordado na próxima 
seção. No entanto, essas questões teóricas contribuem para analisar algumas tendências que podem sedimentar uma análise que permita compreender o recente comportamento das empresas multinacionais e que, em função da complexidade do sistema internacional, não está atrelado apenas às questões econômicas aparentes, mas também a outros fatores, como por exemplo, a atuação dos Estados num contexto de ampla concorrência internacional para o acolhimento desses capitais.

Em geral, o que se pode inferir dessa discussão é que a integração funcional das empresas multinacionais tem sido fundamental para caracterizar o atual contexto da globalização, que cada vez mais se baseia numa cadeia de produção que interliga uma sequência de funções operacionais, na qual cada etapa tem agregado valor ao processo de produção de bens e serviços. Por sua vez, essa cadeia de produção traz à tona a necessidade de compreender dois importantes pontos tais como a maneira como ela é coordenada e regulada, bem como a sua configuração geográfica, sucinta e parcialmente indicada acima.

Mas no que tange ao primeiro aspecto, as cadeias de produção dispostas pelas empresas multinacionais são caracterizadas pelo seu poder de coordenar e controlar as operações em mais de um país, vindo a desenvolver, para tanto, mecanismos cada vez mais sofisticados de relações intra e inter-organizacionais, moldando as condições que são próprias da atual configuração do sistema econômico. Neste sentido, essas empresas devem ser avaliadas não apenas pelos seus ativos tangíveis, mas também pela sua capacidade de envolvimento numa teia de relações de colaboração por diversas partes do globo.

Como a atividade das empresas multinacionais implica as escolhas exportação ou internalização do processo produtivo, deve-se afirmar, também, que a globalização se apoia em diferentes formas de coordenação, que exprimem verdadeiras redes de relações intra e entre firmas que, dada a hierarquia do sistema econômico, são estruturadas a partir de distintos graus de poder e influência. Em função disso, considera-se que essas redes são dinâmicas e estão em contínuo estado de mutação.

Assim sendo, é importante se fazer uma divisão entre os tipos de cadeias produtivas, para que as relações do sistema sejam compreendidas dentro da lógica da globalização. Baseando-se em Gereffi (apud DICKEN, 1998), essas cadeias, grosso modo, são decompostas em dois níveis: $i$ ) o primeiro se refere a setores em que prevalecem os grandes varejistas, nos quais as marcas dos comerciantes e das sociedades comerciais desempenham um papel fundamental na formatação das redes de produção, que devem ser descentralizadas a partir de sua variedade de países exportadores; e, $i$ ) no segundo nível as cadeias de produção tem como principal característica serem altamente influenciadas pelos processos regulatórios, o que significa guardarem uma estreita relação com os Estados, o que corrobora a atuação dessas instituições e do papel político dos governos dentro do sistema econômico internacional.

Admite-se, portanto, que esse conjunto de fatores tem contribuído para a descentralização da cadeia de produção das empresas multinacionais, de tal modo que as estruturas geográfica, econômica e política se tornam centrais para a formatação dos seus arranjos organizacionais, os quais são determinados pelas tecnologias, sobretudo de transportes e de comunicações, que permitem ampliar e diversificar as atividades empresariais. Uma das principais consequências dessa relação é a ampliação da complexidade das relações que envolvem as decisões empresariais, ao estabelecer vários tipos de jogos entre as empresas e os Estados, dando forma a uma interação triangular: empresa-empresa, Estado-Estado e empresaEstado.

Essa interação, de acordo com Dicken (1998), é responsável pelo que se denomina uma nova geoeconomia, que está em constante reestruturação, e que ocorre a partir das ações tanto das empresas quanto dos Estados, formando um emaranhado de relações dinâmicas. Essas relações exprimem tanto um lado conflituoso quanto colaborativo para as três formas de interação, uma vez que envolvem interesses que podem ser cooperativos ou competitivos, 
gerando rivalidades ou conluios, o que exprime um relacionamento dialético. Como exemplo dessa condição, destaca-se a interação entre empresas-Estados, na qual as primeiras se sujeitam às condições impostas pelos Estados, mesmo em condições não ideais, quando as suas escolhas estão condicionadas ao fornecimento da infraestrutura física necessária, do sistema de proteção jurídica e dos mecanismos institucionais para o fornecimento contínuo de trabalhadores educados, entre outros fatores que lhes sejam vantajosos.

Logo, as decisões de investimentos, que se exprimem nas recentes tendências dos fluxos de IED, deixam claro que as fronteiras nacionais ainda compõem as efetivas diferenças em termos de política econômica mundial, pois constituem um dos principais fatores determinantes das escolhas locacionais das empresas, formatando as condições que influenciam diretamente o fluxo de IED. Esse ponto de vista também vem ao encontro da hipótese de que as multinacionais atuam expandindo as economias nacionais, mas também as explorando, pois ao mesmo tempo em que podem contribuir para o crescimento econômico do país acolhedor, o influenciam, operando sobre o processo de concorrência global.

Portanto, compreender as principais formas pelas quais as empresas multinacionais afetam os aspectos econômicos, políticos e culturais das economias nacionais, requer compreender a perspectiva do país anfitrião que procura melhorar suas condições produtivas a partir do acolhimento dessas empresas; e, dessas empresas que, em geral, procuram uma nova base produtiva para ampliar suas operações e dar vazão aos seus processos de acumulação.

O estabelecimento de uma atividade no exterior, por parte de uma multinacional, tende a carregar um conjunto procedimentos (financeiros, tecnológicos, gerenciais, marketing) para o país receptor desse capital, que, por sua vez, é influenciado por esses. Lembrando que as empresas multinacionais podem se estabelecer por meio das operações de fusões e aquisições, bem como a partir da implantação de uma fábrica totalmente nova cujos benefícios para os países de acolhimento geralmente são mais significativos pois não implicam transferência de capacidades produtivas já existentes, mas ampliação da capacidade produtiva do país.

Aqui cabe destacar a inovação trazida pelos estudos da Uppsala University, de Johanson e Vahlne (1977), que observam ser a internacionalização resultado de uma sequência lógica de comprometimento internacional com aquisição gradual de conhecimento sobre mercados estrangeiros. Sendo continuados pelos estudos que constituiriam a Escola Nórdica de Negócios Internacionais, de Johanson e Mattsson (1988), as teorias sobre o IED passariam a estar bastante centradas nas estratégias de entrada de empresas em mercados estrangeiros e, acima de tudo, nas decisões levadas a efeito para tanto.

Nesse sentido, vale ressaltar que alguns autores observaram que, ao contrário dos pressupostos das teorias de negócio internacional convencionais, muitas empresas chinesas se deslocaram para o exterior não para explorar uma vantagem competitiva alcançada no mercado doméstico, mas para evitar desvantagens competitivas na operação exclusiva no mercado doméstico (OLIVEIRA: 2013, p. 23).

Ao mesmo tempo, ainda segundo Oliveira (2013, p. 24), Dunning, Kim e Park afirmam que ao contrário das empresas multinacionais dos países desenvolvidos, as empresas multinacionais dos países em desenvolvimento buscam investir no estrangeiro assim que tem oportunidade e muitas já nascem internacionalizadas, não buscando se consolidar no mercado interno para depois se internacionalizarem.

Entender esse processo a partir de sua realização é, portanto, fundamental para a compreensaão do caso brasileiro.

Uma vez feitas as discussões iniciais, apresentar-se-á a avaliação para o caso brasileiro, que envolve identificar as relações setoriais entre a entrada e saída desses capitais, de tal modo que se possam obter algumas respostas no que tange às decisões envolvendo as exportações dessa modalidade de capital. Para tanto, a seção a seguir vai apresentar uma forma alternativa 
de tratar a questão, realizada a partir do cálculo do indicador denominado Índice de Grubel e Lloyd, cuja metodologia está descrita na seção que segue.

\section{Metodologia: o Índice de Grubel e Lloyd}

Para a avaliação dos estoques de influxos e afluxos de investimento direto no Brasil por setor de atividade, será aplicado o índice de Grubel e Lloyd, utilizado extensivamente a partir da década de 1970 no campo da economia internacional para classificação do comércio em intraindústria (baseado em economias de escala e diferenciação do produto) ou interindústria (baseado na teoria das vantagens comparativas), conforme Grubel e Lloyd (1975). O índice foi posteriormente adaptado para itens do balanço de pagamentos dos países conforme Grubel (2002).

O índice original, que tinha como objetivo avaliar similaridades, em termos setoriais, no comércio internacional, pode ser apresentado sob o seguinte formato:

$$
\mathrm{I}_{\mathrm{CI}}=\frac{\sum_{i=1}^{n}\left(x_{i}+m_{i}\right)-\sum_{i=1}^{n}\left|x_{i}-m_{i}\right|}{\sum_{i=1}^{n}\left(x_{i}+m_{i}\right)} \quad \text { em que } 0 \leq \mathrm{I}_{\mathrm{CI}} \leq 1
$$

\footnotetext{
Em que:

$\mathrm{I}_{\mathrm{CI}}=$ índice de comércio intraindústria no setor

$\mathrm{x}_{\mathrm{i}}=$ exportações do produto ou setor

$\mathrm{m}_{\mathrm{i}}=$ importações do produto ou setor
}

A equação original de Grubel e Lloyd (1975) equivale ao resultado da equação (1) multiplicado por 100. Assim, o resultado sempre se situará no intervalo [1, 100]. Nos estudos recentes, entretanto, o fator foi suprimido e o resultado passou a se dar no intervalo [0,1]. Assim, quando o valor das exportações de uma determinada indústria for próximo ao valor das importações, o resultado do índice será próximo de um. Por outro lado, quanto maior a distância entre o valor das exportações em relação ao valor das importações, mais próximo de zero será o resultado do índice.

Em uma reformulação do índice, Grubel (2002) fez uma adaptação considerando os fluxos representados no balanço de pagamentos. Neste sentido e para os propósitos deste estudo, o índice Grubel e Lloyd para os estoques setoriais de investimento direto será adaptado de acordo com a seguinte expressão:

$$
\mathrm{I}_{\mathrm{IDS}}=\frac{\left(I D S_{\text {out }}+I D S_{\text {in }}\right)-\left|I D S_{\text {out }}-I D S_{\text {in }}\right|}{\left(I D S_{\text {out }}+I D S_{\text {in }}\right)}
$$

Em que:

$\mathrm{I}_{\mathrm{IDS}}=$ Índice setorial de investimento direto

$\mathrm{IDS}_{\text {out }}=$ Investimento direto setorial de residentes no exterior

IDS $_{\text {in }}=$ Investimento direto setorial de estrangeiros no Brasil

De acordo com o índice Grubel e Lloyd adaptado, é possível calcular os estoques de entrada e saída de investimento direto e compreender a dinâmica dos setores para uma determinada economia. O resultado da equação dois sempre se situará no intervalo $[0,1]$. Quando o estoque for predominante em um sentido, apenas entrada ou apenas saída, o resultado 
do cálculo se aproximará de zero. Por outro lado, quanto mais próximos os valores de estoques de entrada e de saída, mais próximo de um será o resultado da equação.

Cumpre destacar que o índice possui algumas limitações. Se um país tiver predominantemente estoques de saída, ou de entrada, o resultado será o mesmo, próximo de zero, independentemente da direção. Além disso, considerando um país que tem valores próximos de estoques de entrada e saída e uma queda dos estoques nos dois sentidos em um determinado ano, o índice continuará próximo de um. Por ser um índice relativo, sua interpretação merece cautela. Apesar da ressalva, a aplicação do índice GL pode ser útil em comparações e análises de estoques setoriais de investimento direto, entre outras questões.

Para o cálculdo do índice GL setorial serão utilizados os dados do Censo do Capital Estrangeiro e das Estatísticas de Capitais Brasileiros no Exterior do Banco Central do Brasil. Apesar das discussões envolverem os fluxos de IED (entrada e saída), o presente estudo utilizase de dados de estoque, uma vez que as informações desagregadas setorialmente estão disponíveis apenas dessa forma.

\section{Análise dos resultados e discussão}

Considerando que a análise alternativa que se está fazendo no presente trabalho envolve comparar os fluxos de entrada e saída de IED, com vistas a encontrar algumas evidências que corroborem parte das teorias aqui abordadas, vale realizar, previamente, uma rápida análise dos estoques de IED por setor de atividade, para que em seguida sejam feitas as avaliações dos resultados obtidos a partir do Índice de Grubel e Lloyd. 
Tabela 2 - Estoque de IED (Entrada e Saída) em US\$ milhões e participação relativa - 2014

\begin{tabular}{|c|c|c|c|c|c|}
\hline & SETORES DE ATIVIDADE & $\begin{array}{c}\text { ENTRADA } \\
2014\end{array}$ & $\%$ & $\begin{array}{c}\text { SAIDA } \\
2014\end{array}$ & $\%$ \\
\hline \multirow{6}{*}{ 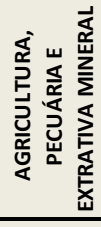 } & Extração de petróleo e gás natural & 33.900 .697 .947 & $6,38 \%$ & 16.581 .521 .592 & $6,15 \%$ \\
\hline & Extração de minerais metálicos & 18.353 .659 .840 & $3,45 \%$ & 32.439 .334 .769 & $12,02 \%$ \\
\hline & Agricultura, pecuária e serviços relacionados & 4.851 .340 .455 & $0,91 \%$ & 1.627.191.020 & $0,60 \%$ \\
\hline & Extração de minerais não-metálicos & 4.138 .162 .602 & $0,78 \%$ & 552.448 .848 & $0,20 \%$ \\
\hline & Produção florestal & 1.811 .810 .293 & $0,34 \%$ & 4.219 .408 & $0,00 \%$ \\
\hline & Pesca e aquicultura & 5.334 .029 & $0,00 \%$ & 0 & $0,00 \%$ \\
\hline \multirow{20}{*}{ 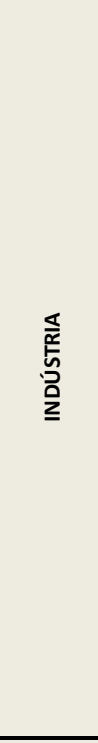 } & Alimentos e bebidas & 73.849 .975 .406 & $13,90 \%$ & 16.443 .091 .212 & $6,09 \%$ \\
\hline & Metalurgia & 21.422.027.311 & $4,03 \%$ & 12.543 .945 .201 & $4,65 \%$ \\
\hline & Veículos automotores, reboques e carrocerias & 18.454 .956 .278 & $3,47 \%$ & 575.495 .467 & $0,21 \%$ \\
\hline & Produtos químicos & 18.103.972.102 & $3,41 \%$ & 288.503.709 & $0,11 \%$ \\
\hline & Máquinas e equipamentos & 9.832 .731 .175 & $1,85 \%$ & 351.203 .793 & $0,13 \%$ \\
\hline & Produtos do fumo & 9.338 .980 .381 & $1,76 \%$ & 18.782 .057 & $0,01 \%$ \\
\hline & Produtos de borracha e de material plástico & 7.087.145.425 & $1,33 \%$ & 552.447 .206 & $0,20 \%$ \\
\hline & Celulose, papel e produtos de papel & 6.904 .698 .172 & $1,30 \%$ & 25.035 .200 & $0,01 \%$ \\
\hline & Equipamentos de informática, produtos el etrônicos e ópticos & 6.018 .150 .782 & $1,13 \%$ & 122.887 .176 & $0,05 \%$ \\
\hline & Coque, derivados de petróleo e biocombustíveis & 5.177 .485 .001 & $0,97 \%$ & 0 & $0,00 \%$ \\
\hline & Produtos minerais não-metálicos & 4.699 .753 .104 & $0,88 \%$ & 9.578 .487 .221 & $3,55 \%$ \\
\hline & Máquinas, aparel hos e materiais elétricos & 4.308 .706 .831 & $0,81 \%$ & 1.157.415.032 & $0,43 \%$ \\
\hline & Produtos de metal & 3.216 .587 .841 & $0,61 \%$ & 296.926 .183 & $0,11 \%$ \\
\hline & Outros equipamentos de transporte & 2.793 .567 .122 & $0,53 \%$ & 641.630 .992 & $0,24 \%$ \\
\hline & Produtos têxteis & 1.469 .910 .931 & $0,28 \%$ & 403.862 .924 & $0,15 \%$ \\
\hline & Produtos de madeira & 893.981 .801 & $0,17 \%$ & 14.313 .197 & $0,01 \%$ \\
\hline & Confecção de artigos de vestuário e acessórios & 486.800 .513 & $0,09 \%$ & 23.046 .125 & $0,01 \%$ \\
\hline & Impressão e reprodução de gravações & 205.882 .140 & $0,04 \%$ & 31.939 .881 & $0,01 \%$ \\
\hline & Preparação de couro e fabricação de artefatos de couro e calça & 126.491 .316 & $0,02 \%$ & 145.017 .026 & $0,05 \%$ \\
\hline & Fabricação de móveis & 62.453 .996 & $0,01 \%$ & 0 & $0,00 \%$ \\
\hline \multirow{17}{*}{$\begin{array}{l}\text { 总 } \\
\text { 总 } \\
\text { ún }\end{array}$} & Serviços financeiros e atividades auxiliares & 79.731 .619 .083 & $15,00 \%$ & 123.379 .667 .747 & $45,72 \%$ \\
\hline & Telecomunicações & 39.798.339.592 & $7,49 \%$ & 2.389 .394 .325 & $0,89 \%$ \\
\hline & Comércio, exceto veículos & 35.031 .843 .669 & $6,59 \%$ & 8.438 .551 .291 & $3,13 \%$ \\
\hline & Eletricidade, gás e outras utilidades & 23.525 .622 .032 & $4,43 \%$ & 111.725 .693 & $0,04 \%$ \\
\hline & Seguros, resseguros, previdência complementar e planos de saú & 16.453 .217 .258 & $3,10 \%$ & 178.291 .937 & $0,07 \%$ \\
\hline & Atividades imobiliárias & 14.079.576.207 & $2,65 \%$ & 2.111 .664 .816 & $0,78 \%$ \\
\hline & Atividades de sedes de empresas e de consultoria em gestão de & 14.637 .961 .723 & $2,75 \%$ & 10.256 .378 .882 & $3,80 \%$ \\
\hline & Transporte & 8.396 .539 .922 & $1,58 \%$ & 526.292 .026 & $0,20 \%$ \\
\hline & Construção de edifícios & 8.619 .610 .788 & $1,62 \%$ & 5.399 .569 .152 & $2,00 \%$ \\
\hline & Serviços de tecnologia da informação & 5.384 .128 .921 & $1,01 \%$ & 154.560 .634 & $0,06 \%$ \\
\hline & Comércio e reparação de veículos & 1.277.296.771 & $0,24 \%$ & 49.390 .748 & $0,02 \%$ \\
\hline & Educação & 987.673 .188 & $0,19 \%$ & 3.936 .906 & $0,00 \%$ \\
\hline & Saúde & 485.454 .367 & $0,09 \%$ & 25.453 .119 & $0,01 \%$ \\
\hline & Atividades es portivas e de recreação e lazer & 468.313 .117 & $0,09 \%$ & 52.578 .434 & $0,02 \%$ \\
\hline & Agências de viagens e operadores turísticos & 246.792 .083 & $0,05 \%$ & 2.094 .720 & $0,00 \%$ \\
\hline & Pesquisa e desenvolvimento científico & 212.772 .131 & $0,04 \%$ & 90.235 .751 & $0,03 \%$ \\
\hline & Serviços pessoais & 119.078 .776 & $0,02 \%$ & 2.648 .134 .806 & $0,98 \%$ \\
\hline \multicolumn{2}{|r|}{ TOTAL } & 531.444 .805 .550 & - & \multicolumn{2}{|l|}{ 269.831.742.878 } \\
\hline
\end{tabular}

Fonte : Banco Central do Brasil (2016)

A Tabela 2 demonstra tais estoques para as atividades econômicas vinculadas aos três grandes setores: Agricultura, Pecuária e Extrativa Mineral, Indústria e Serviços. E os principais destaques a serem feitos são as atividades de Serviços Financeiros, Alimentos e Bebidas, Comércio de Veículos e Extração de Petróleo, uma vez que se identificaram nesses segmentos as maiores participações relativas tanto nos estoques de entrada quanto de saída. Assim sendo, verifica-se que os principais setores acolhedores de IED também são os principais exportadores desses capitais, fato que será analisado com maiores detalhes a partir dos resultados do Índice de Grubel e Lloyd, que seguem. 
A aplicação do índice, conforme a equação 2 apresentada anteriormente, mostrou resultados interessantes em termos da evolução dos estoques de investimento direto (entrada e saída) em termos setoriais no período 2000-2014. Os resultados podem ser observados na Tabela 3, que separa os setores de atividade em três grandes grupos: agricultura/pecuária/extrativa mineral, indústria e serviços. Em alguns anos não foi possível calcular o índice pois não havia estoque de entrada ou de saída em determinados setores.

Tabela 3 - Índice GL - Estoques de Investimento Direto (exterior e local) por setores de atividade (2000-2014)

\begin{tabular}{|c|c|c|c|c|c|}
\hline \multirow{2}{*}{\multicolumn{2}{|c|}{ S ETORES DE ATIVIDADE }} & \multicolumn{4}{|c|}{ ÍNDICE GL } \\
\hline & & \multirow{2}{*}{$\begin{array}{l}\mathbf{2 0 0 0} \\
0,79\end{array}$} & \multirow{2}{*}{$\frac{2005}{0,94}$} & \multirow{2}{*}{$\begin{array}{l}\frac{2010}{0,23} \\
\end{array}$} & \multirow{2}{*}{$\begin{array}{l}\mathbf{2 0 1 4} \\
0,66\end{array}$} \\
\hline 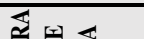 & Extração de petróleo e gás natural & & & & \\
\hline$\geq \leq \geq=$ & Extração de minerais metálicos & & 0,53 & 0,75 & 0,72 \\
\hline క气急 & Agricultura, pecuária e serviços relacionados & 0,54 & 0,17 & 0,07 & 0,50 \\
\hline 已氠 & Extração de minerais não-metálicos & 0,02 & 0,00 & 0,24 & 0,24 \\
\hline 象功之 & Produção florestal & 0,09 & & 0,00 & 0,00 \\
\hline & Pesca e aquicultura & 0,03 & & & \\
\hline \multirow{20}{*}{$\begin{array}{l}\text { 品 } \\
\text { 总 } \\
\text { 旁 }\end{array}$} & Alimentos e bebidas & 0,05 & 0,14 & 0,23 & 0,36 \\
\hline & Metalurgia & 0,09 & 0,46 & 0,47 & 0,74 \\
\hline & Veículos automotores, reboques e carrocerias & 0,05 & 0,01 & 0,04 & 0,06 \\
\hline & Produtos químicos & 0,01 & 0,01 & 0,06 & 0,03 \\
\hline & Máquinas e equip amentos & 0,06 & 0,07 & 0,06 & 0,07 \\
\hline & Produtos do fumo & 0,41 & 0,10 & 0,00 & 0,00 \\
\hline & Produtos de borracha e de material plástico & 0,06 & 0,18 & 0,12 & 0,14 \\
\hline & Celulose, papel e produtos de papel & 0,15 & 0,01 & 0,00 & 0,01 \\
\hline & Equipamentos de informática, produtos eletrônicos e ópticos & 0,00 & 0,01 & 0,00 & 0,04 \\
\hline & Coque, derivados de petróleo e biocombustíveis & 0,00 & & & \\
\hline & Produtos minerais não-metálicos & 0,55 & 0,04 & 0,95 & 0,66 \\
\hline & Máquinas, aparelhos e materiais elétricos & 0,23 & 0,07 & 0,05 & 0,42 \\
\hline & Produtos de metal & 0,33 & 0,80 & 0,05 & 0,17 \\
\hline & Outros equipamentos de transporte & 0,18 & 0,07 & 0,58 & 0,37 \\
\hline & Produtos têxteis & 0,10 & 0,12 & 0,41 & 0,43 \\
\hline & Produtos de madeira & & 0,07 & & 0,03 \\
\hline & Confecção de artigos de vestuário e acessórios & 0,00 & 0,05 & 0,02 & 0,09 \\
\hline & Impressão e reprodução de gravações & 0,00 & 0,10 & 0,22 & 0,27 \\
\hline & Preparação de couro e fabricação de artefatos de couro e calçados & 0,07 & 0,10 & 0,39 & 0,93 \\
\hline & Fabricação de móveis & 0,00 & 0,00 & & \\
\hline \multirow{17}{*}{ 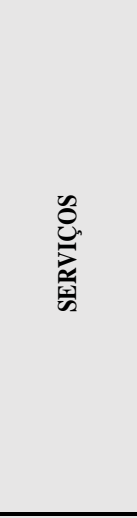 } & Serviços financeiros e atividades auxiliares & 0,96 & 0,92 & 0,74 & 0,79 \\
\hline & Telecomunicações & & & 0,00 & 0,11 \\
\hline & Comércio, exceto veículos & 0,30 & 0,29 & 0,17 & 0,39 \\
\hline & Eletricidade, gás e outras utilidades & 0,01 & 0,00 & 0,06 & 0,01 \\
\hline & Seguros, resseguros, previdência comp lementar e planos de saúde & 0,12 & 0,17 & 0,04 & 0,02 \\
\hline & Atividades imobiliárias & 0,24 & 0,15 & 0,21 & 0,26 \\
\hline & Atividades de sedes de empresas e de consultoria em gestão de empresas & 0,87 & 0,80 & 0,80 & 0,82 \\
\hline & Transporte & 0,76 & 0,76 & 0,04 & 0,12 \\
\hline & Construção de edifícios & 0,51 & 0,58 & 0,20 & 0,77 \\
\hline & Serviços de tecnologia da informação & 0,03 & 0,22 & 0,05 & 0,06 \\
\hline & Comércio e reparação de veículos & 0,14 & 0,19 & 0,07 & 0,07 \\
\hline & Educação & 0,57 & 0,05 & 0,01 & 0,01 \\
\hline & Saúde & & & 0,02 & 0,10 \\
\hline & Atividades esportivas e de recreação e lazer & 0,42 & 0,15 & 0,76 & 0,20 \\
\hline & Agências de viagens e operadores turísticos & 0,68 & 0,01 & 0,07 & 0,02 \\
\hline & Pesquisa e desenvolvimento científico & 0,05 & 0,00 & 0,35 & 0,60 \\
\hline & Serviços pessoais & & & 0,25 & 0,09 \\
\hline \multicolumn{2}{|r|}{ TOTAL } & 0,58 & 0,57 & 0,45 & 0,67 \\
\hline
\end{tabular}

Fonte: Elaborado pelos autores a partir dos dados da UNCTAD e Banco Central do Brasil (2016)

De uma forma geral, percebe-se uma tendência de crescimento do índice de Grubel e Lloyd adaptado em relação aos estoques do setor industrial, enquanto nos setores primário e terciário não houve um comportamento comum, já que alguns setores mostraram crescimento do índice ao mesmo tempo em que outros apresentaram queda. Na maior parte dos setores industriais, como alimentos e bebidas e metalurgia, por exemplo, a tendência foi de crescimento, o que sugere relativo equilíbrio entre os estoques de entrada e saída de investimento direto e um processo de internacionalização das empresas brasileiras. Após um período de ingresso de investimento direto nesses setores na economia brasileira, muitas 
empresas brasileiras iniciaram um processo de internacionalização, o que pode ser visto pelo comportamento do índice.

Em relação ao setor primário, percebe-se, na Tabela 3, o crescimento do índice nos setores de petróleo e gás natural, além de minerais metálicos e não metálicos. No que se refere ao setor terciário, o destaque fica para a construção de edifícios, que mostrou um crescimento no índice de Grubel e Lloyd adaptado de 0,51 em 2000 para 0,77 em 2014. Na maior parte dos setores de atividade, ocorreu uma queda no índice calculado.

Quando se considera a soma de todos os setores, nota-se um crescimento no índice de Grubel e Lloyd, que era de 0,58 em 2000 e teve um resultado de 0,67 em 2014, ainda de acordo com a Tabela 3, o que permite concluir que os estoques de saída de investimento direto (investimento de brasileiros no exterior) se aproximaram dos estoques de entrada (investimento estrangeiro direto).

Figura 1 - Índice Grubel e Lloyd - Estoques de Investimento Direto (exterior e local) em subsetores selecionados no setor primário (2000-2014)

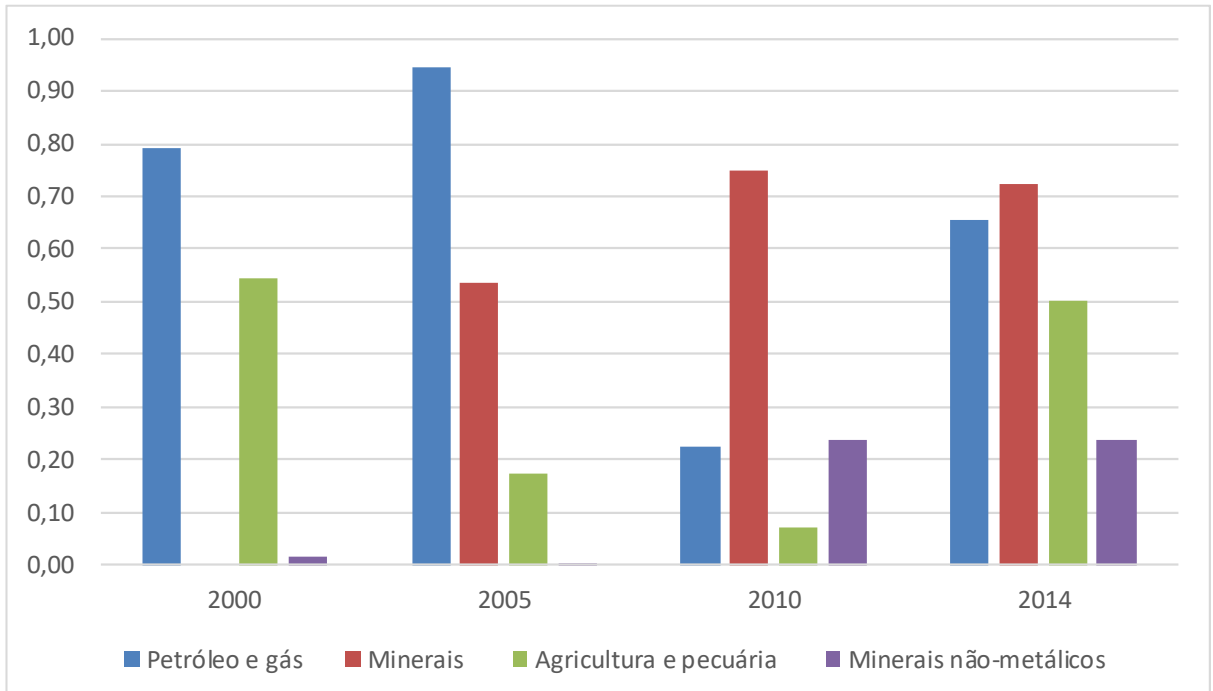

Fonte: Elaborado pelos autores a partir dos dados da UNCTAD e Banco Central do Brasil (2016)

Para uma análise mais detalhada, foram selecionados alguns subsetores do setor Agropecuário e Extrativo Mineral; Indústria; e, Serviços para uma avaliação mais detalhada. Nesse sentido, a Figura 1 apresenta o comportamento do índice Grubel e Lloyd nos quatro períodos e é possível verificar que ocorreu um crescimento no setor minerais e minerais nãometálicos enquanto os setores de petróleo e gás, além de agricultura e pecuária, apresentaram queda.

Com relação à Indústria, percebe-se, de acordo com a Figura 2, que entre os setores selecionados, apenas o setor de celulose e papel apresentou queda, em decorrência de um aumento do estoque de investimentos estrangeiro neste setor de forma concomitante a uma redução do investimento de residentes no exterior. Assim, pode-se afirmar que os estrangeiros ampliaram sua participação no mercado doméstico ao mesmo tempo em que ocorreu um desinvestimento de brasileiros no exterior neste setor. 
Figura 2 - Índice Grubel e Lloyd - Estoques de Investimento Direto (exterior e local) em subsetores selecionados no setor secundário (2000-2014)

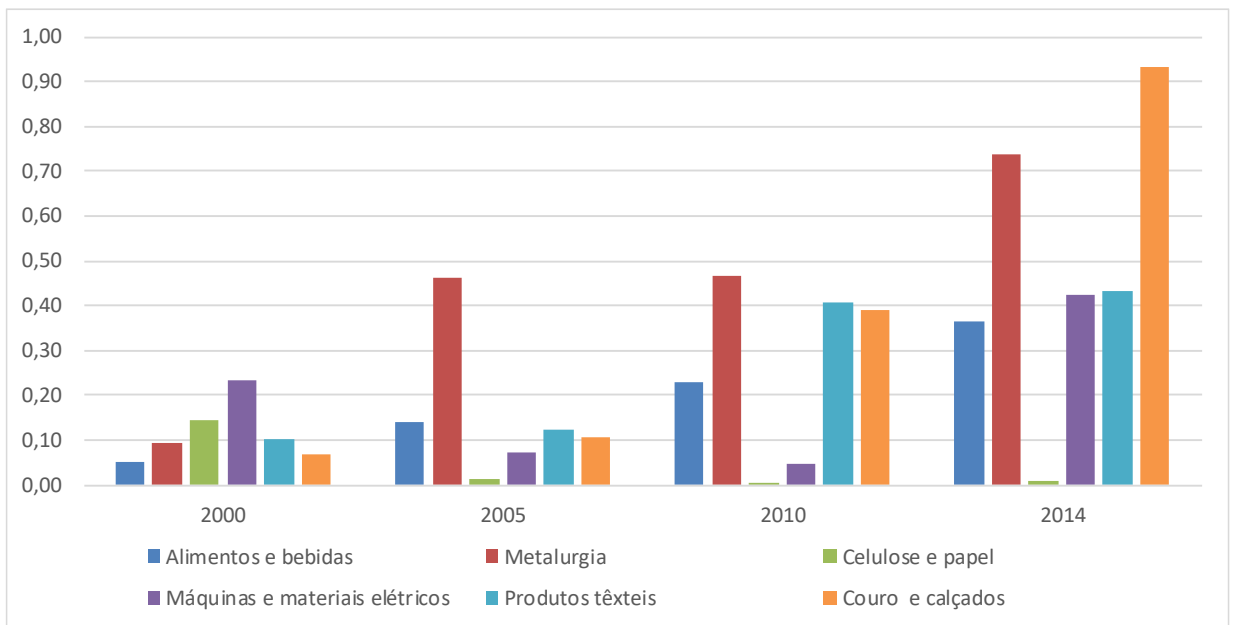

Fonte: Elaborado pelos autores a partir dos dados da UNCTAD e Banco Central do Brasil (2016)

O destaque para o crescimento no setor secundário fica para o setor de couro e calçados, que passou de um índice de 0,07 em 2000 para 0,93 em 2014. Enquanto os estoques de entrada de investimento aumentaram de US\$ 49 milhões para US\$ 126 milhões no período analisado, os estoques de investimentos brasileiros no exterior crescerem de US\$1,7 milhão para US\$145 milhões em 2014.

Figura 3 - Índice Grubel e Lloyd - Estoques de Investimento Direto (exterior e local) em subsetores selecionados no setor terciário (2000-2014)

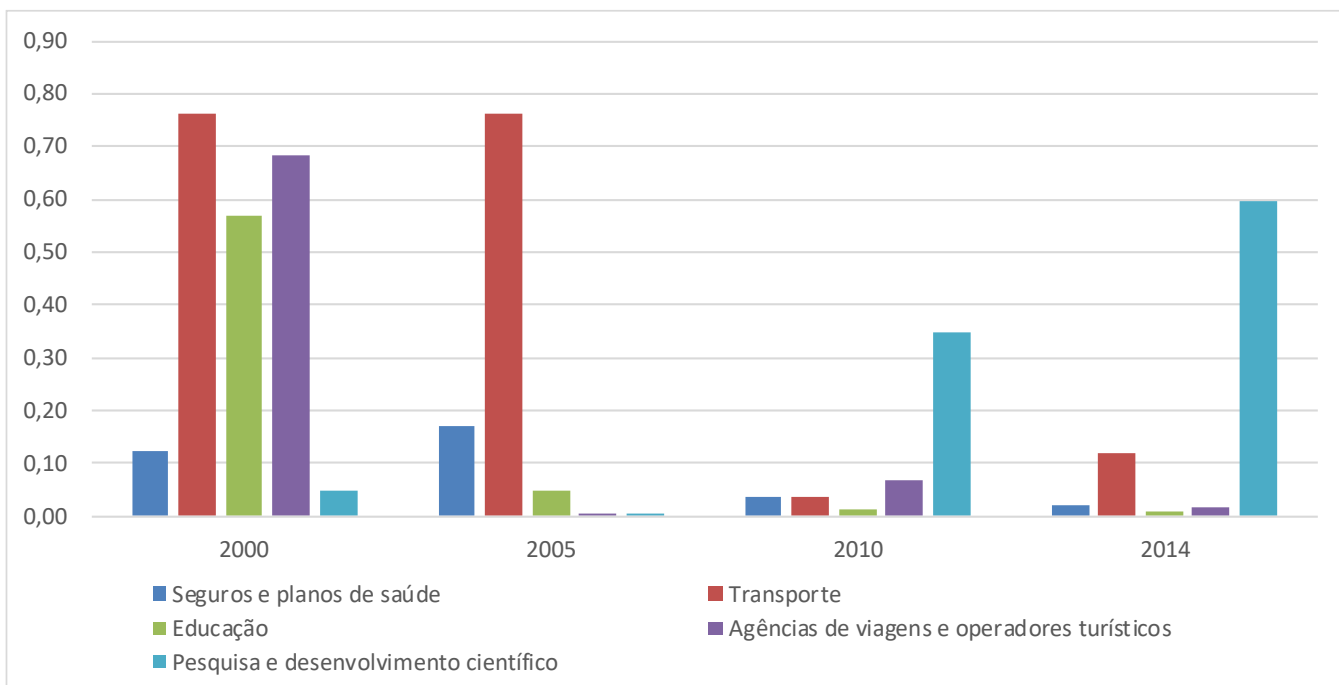

Fonte: Elaborado pelos autores a partir dos dados da UNCTAD e Banco Central do Brasil (2016)

Finalmente, a análise do setor de Serviços indica que houve uma queda no índice em muitos setores de atividade, como seguros e planos de saúde, educação, transporte e agências de viagens e operadores turísticos, conforme pode ser observado na Figura 3. Isso decorre, fundamentalmente, do baixo grau de internacionalização das empresas desses setores. Os investimentos de brasileiros no exterior não acompanham o mesmo ritmo de crescimento da entrada de grupos estrangeiros no Brasil, gerando desequilíbrio entre os estoques de entrada e saída. 
Ainda em relação ao setor de serviços, chama a atenção o comportamento do setor de pesquisa e desenvolvimento científico, cujo índice evoluiu positivamente no período não somente pelo elevado crescimento de investimento de residentes no exterior, como também pela queda de estoques de estrangeiros no Brasil.

\section{Considerações Finais}

De acordo com a breve discussão teórica que aborda alguns dos fatores determinantes das movimentações de IED, verificou-se que são diversos os elementos a serem considerados, sobretudo no caso dos países em desenvolvimento, que requerem uma avaliação mais detida das particularidades de suas economias.

Especificamente para o objeto de análise do presente artigo (o Brasil), buscou-se por meio de uma avaliação alternativa (o Índice Grubel e Lloyd) identificar algumas dessas especificidades, por meio de evidências setoriais que relacionam a entrada de empresas estrangeiras no país à atuação de empresas nacionais no exterior.

Neste sentido, identificou-se que as atividades do chamado setor primário com maior convergência foram a de Petróleo e Gás, o que se explica não apenas pela entrada de um volume considerável de capitais estrangeiros para atuação no setor, mas também pela atuação da Petrobrás em diversos países do mundo. Outro exemplo em que a entrada de IED tem mostrado um expressivo interesse do capital estrangeiro é a exploração de minérios, ao mesmo tempo em que o Brasil possui um dos maiores players do segmento no mundo, a Vale, que está presente em diversos continentes com o objetivo de ampliar sua participação do mercado mundial. O setor agropecuário também apresenta resultados convergentes, cabendo lembrar que cada vez mais a atividade é dominada por grandes produtores que controlam extensas áreas rurais, fato que tem despertado o interesse de investidores estrangeiros, tanto que o estoque dessas atividades apresentou uma taxa de crescimento três vezes maior do que a taxa de crescimento do estoque total de IED no País entre os anos de 2000 e 2014.

Para esse setor, as evidências são condizentes com parte das argumentações teóricas que explicam as decisões empresariais de atuar em outros países em função da forte orientação para exportação dos bens produzidos, sendo que esses setores, com a exceção da atividade petrolífera, geralmente utilizam tecnologias relativamente estáveis e pouco sofisticadas, bem como fazem uso de uma força de trabalho barata.

Para a indústria identificou-se que os setores de Metalurgia, Alimentos e Bebidas, Produtos Têxteis, Couro e calçados apresentaram o Índice Grubel e Lloyd relativamente convergentes, apesar de oscilar bastante ao longo do período analisado, mas com uma tendência crescente no último ano analisado (2014). Esses setores guardam uma forte relação com parte das explicações que tratam de identificar as atividades mais tradicionais do setor manufatureiro, que utilizam uma tecnologia padronizada e requerem constantes investimentos na diferenciação de produto.

Por fim, o setor de serviços apresenta uma tendência declinante do Índice Grubel e Lloyd, mesmo para aquelas atividades que inicialmente registravam uma elevada convergência. Excessão deve ser feita às atividades de $\mathrm{P} \& \mathrm{D}$, mas cabe ressaltar que as mesmas são consideradas incipientes quando considerados os valores totais de IED (in e out).

De uma forma geral, o Brasil tem um comportamento agregado para o Índice Grubel e Lloyd que não é semelhante ao que ocorre nos países desenvolvidos, ou até mesmo com a China. Todavia, apresenta alguns setores em que a convergência do indicador é relevante, mostrando que os setores que mais recebem capital estrangeiro também têm buscado, por meio das empresas sediadas no País, atuar produtivamente no exterior, fato que entre outras coisas é condizente com um movimento global de integração produtiva, o que por sua vez reforça a necessidade de se discutir a internacionalização a partir da perspectiva da Uppsala University e 
da Escola Nórdica de Negócios Internacionais que evidenciam o comprometimento internacional e a aquisição de conhecimentos sobre mercados externos e as estratégias e as tomadas de decisão de exportar parte de seu processo produtivo com vistas a explorar vantagens em outros países e evitar possíveis desvantagens oriundas da manutenção do processo produtivo no mercado doméstico.

No que concerne à situação brasileira, observa-se, conforme os resultados do índice Grubel \&Lloyd, uma lógica identificada com a dos países em desnvolvimento, segundo a qual as empresas que internacionalizam seu processo produtivo, o fazem assim que tem oportunidade, ou já nascem internacionalizadas, sem antes consolidar sua posição no mercado interno.

\section{REFERENCIAS}

ALMEIDA, André. Internacionalização de empresas brasileiras: perspectivas e riscos. Elsevier, 2007.

BANCO CENTRAL DO BRASIL (BCB). Disponível em: <www.bcb.gov.br>. Acesso em 08 de abril de 2016.

BUCKLEY, P.; CASSON, M. The future of the multinational enterprise. London, MacMillan, 1976.

CARNEIRO, Jorge Manuel Teixeira; DIB, Luis Antônio. Avaliação comparativa do escopo descritivo e explanatório dos principais modelos de internacionalização de empresas. Internext, v. 2, n. 1, p. 1-25, 2008.

CAVES, R. E. International corporations: the industrial economics of foreign investment. Econômica, London, v.38, 1971.

MACADAR, Beky Moron de. A internacionalização de grandes empresas brasileiras e as experiências do Grupo Gerdau e da Marcopolo. Ensaios FEE, v. 30, n. 1, p. 7-34, 2009.

DICKEN, P. Global Shift: Transforming the World Economy. London: Paul Chapman Publishing, 1998.

DUNNING, J. Multinational enterprise and the global economy. Wokinghan: AddisonWesley, 1993.

GRUBEL, H. Intra-Industry Trade in Assets. In H. O. Lee e P. J. Lloyd (Eds.) Frontiers of Research in Intra-Industry Trade (pp. 273-290). New York: Palgrave Macmillan, 2002.

GRUBEL, H.; LLOYD, P. Intra-Industry Trade: the Theory and Measurement of International Trade in Differentiated Products. Grã-Bretanha: Halsted Press, 1975.

HYMER, Stephen. Empresas multinacionais: a internacionalização do capital. Rio de Janeiro: Graal, 1983.

HILAL, Adriana; HEMAIS, Carlos A. O processo de internacionalização na ótica da escola nórdica: evidências empíricas em empresas brasileiras. Revista de Administração Contemporânea, v. 7, n. 1, p. 109-124, 2003.

HONÓRIO, Luiz Carlos. Determinantes organizacionais e estratégicos do grau de internacionalização de empresas brasileiras. RAE-Revista de Administração de Empresas, v. 49, n. 2, p. 162-175, 2009. 
JOHANSON, J.; MATTSSON, L-G. Internationalization in industrial system - a network approach. In: N. HOOD \& J.-E Vahlne (Eds.). Strategies in Global Competition, Croom Helm, 1988.

JOHANSON, J.; VAHLNE, J. The Internationalization process of the firm: A model of knowledge development and increased market commitments. Journal of International Business Studies, v. 8, n. 1, p. 23-32, 1977.

KINDLEBERGER, Charles. The World in Depression (1929-1939). Berkeley: University of California Press, 1974.

MACADAR, Beky Moron de. A internacionalização de grandes empresas brasileiras e as experiências do Grupo Gerdau e da Marcopolo. Ensaios FEE, v. 30, n. 1, p. 7-34, 2009.

OLIVEIRA, Mariana Sandoval. O Processo de Internacionalização de Empresas da China: Estratégias Empresariais e Diplomacia Econômica. Programa de Estudos Pós-Graduados em Economia (Dissertação de Mestrado), Pontifícia Universidade Católica de São Paulo, 2013.

PASQUALOTTO, Carina; UGALDE, Marise Mainieri de. Adaptações de produto no processo de internacionalização de empresas gaúchas do setro moveleiro. Internext: Revista Electrônica de Negócios Internacionais da ESPM, v. 5, n. 2, 2010.

ROCHA, A. D. et al. Processo de internacionalização de empresas nascidas globais: estudo de casos no setor de software. Enanpad XXIX. Anpad, Brasília, 2005.

UNITED NATIONS CONFERENCE ON TRADE AND DEVELOPMENT (UNCTAD). Disponível em: <www.unctad.org>. Acesso em 02 de abril de 2016.

VERNON, R. International Investment and international trade in the product cycle. Quarterly Journal of Economics. MA: MIT Press, 1966. 